\title{
The Segregation of the $2 \mu$-based Yeast Plasmid pJDB248 Breaks Down under Conditions of Slow, Glucose-limited Growth
}

\author{
By VIRGINIA C. BUGEJA, ${ }^{*}$ MATTHEW J. KLEINMAN, $\dagger$ \\ PETER F. STANBURY AND ELLIOT B. GINGOLD \\ Division of Biological Sciences, Hatfield Polytechnic, Hatfield AL10 9AB, UK
}

(Received 25 May 1989; accepted 17 July 1989)

\begin{abstract}
The stability of the $2 \mu$-based yeast plasmid pJDB248 in Saccharomyces cerevisiae S150-2B(cir ${ }^{0}$ ) was investigated in glucose-limited chemostat culture. Plasmid-free cells were detected by loss of (plasmid-encoded) leucine prototrophy and confirmed by colony hybridization. The plasmid was considerably more stable at a high dilution rate $\left(0.12 \mathrm{~h}^{-1}\right)$ than at a lower dilution rate $\left(0.05 \mathrm{~h}^{-1}\right)$. The average plasmid copy number in the cells retaining the plasmid remained constant at approximately 50 in the high dilution rate culture whereas it rose to almost 600 in the slow dilution rate culture. However, in both cultures the overall plasmid level in the total population remained constant, indicating that plasmid segregation breaks down at the low growth rate. Similar experiments on the native $2 \mu$ plasmid demonstrated high stability and no significant differences between the high and low growth rate cultures. It is postulated that the difference in behaviour between the native and chimeric plasmids is related to an interaction between the growth conditions and the loss of the $D$ gene product.
\end{abstract}

\section{INTRODUCTION}

The yeast Saccharomyces cerevisiae is being used extensively as a microbial system for the expression of cloned eukaryotic genes. As a result, for both fundamental and commercial reasons we need to understand the mechanism for propagating cloning vectors with both high copy numbers per cell and high mitotic stability. The endogenous $2 \mu$ plasmid of $S$. cerevisiae has formed the basis for many cloning vectors in yeast (Broach, 1983). It is a circular DNA molecule, stably maintained in multiple copies in the nucleus of nearly all strains of $S$. cerevisiae (for review see Futcher, 1988). However, $2 \mu$-based chimeric plasmids, which contain either part or all of the $2 \mu$ DNA to promote their replication (Broach, 1981), do not retain the high stability shown by the native $2 \mu$ plasmid (Futcher \& Cox, 1984). Consequently, problems occur when strains carrying such plasmids are used in non-selective growth conditions in large-scale fermentation processes, where it is particularly desirable to maintain high plasmid stability.

Extensive studies on plasmid stability in bacterial systems have demonstrated that both genetic and physiological factors affect the level of plasmid retention in a culture. These have included plasmid replication rate, segregation, copy number and culture growth rate, as well as the effect the plasmid has on the host cell (Caulcott, 1984). Continuous cultures have proved very important tools in these studies since they allow the maintenance of cell populations under constant physiological conditions over many generations.

In $S$. cerevisiae, the maintenance of $2 \mu$ and $2 \mu$-based chimeric plasmids in cell populations has been investigated during batch growth (Futcher \& Cox, 1984) and in continuous cultures (Walmsley et al., 1983; Mead et al.,1986a, b; Kleinman et al., 1986). The behaviour of different plasmids has been found to vary considerably and factors influencing stability have included

† Present address: School of Biological Sciences, Queen Mary College, London, UK.

$\ddagger$ Present address: Department of Biotechnology, South Bank Polytechnic, London, UK. 
incompatibility, i.e. the presence of other plasmids in the cell such as the native $2 \mu$ plasmid (Dobson et al., 1980; Walmsley et al., 1983), the rate at which plasmid-free cells are generated from plasmid-containing cells (segregational instability) and the difference in the growth rates of the plasmid-free and plasmid-containing cells (selection).

Futcher \& Cox (1983) showed that for both the native $2 \mu$ plasmid and $2 \mu$-based chimeric plasmids, instability is far higher than expected. As a result, these authors hypothesized that plasmid partitioning is less efficient than would be expected from a purely random segregation and that some biological properties of the system must increase the rate of segregation of plasmid-free cells.

The $2 \mu$ plasmid has been used in growth rate competition experiments between plasmid-free $\left(\mathrm{cir}^{0}\right)$ and plasmid-containing $\left(\mathrm{cir}^{+}\right)$cells in isogenic strains of $S$. cerevisiae (Futcher \& Cox, 1983; Mead et al., 1986a). Results from these studies show that plasmid-free cells have a slight (approximately $1 \%$ ) growth-rate advantage over plasmid-containing cells. Passage of a haploid host through the stationary phase of growth increased overall stability; furthermore the $2 \mu$ piasmid was more stable in diploid cells (Mead et al., 1986b). In a diploid strain with the $2 \mu$ chimeric plasmid pJDB219, which contains the entire $2 \mu$ DNA sequence, the plasmid was more stable than in either of the two haploids from which the diploid was derived.

Our own experiments using glucose-limited continuous cultures have shown that growth conditions play a significant role in the stability of the $2 \mu$-based chimeric plasmid pJDB248 in $S$. cerevisiae (Kleinman et al., 1986). This plasmid contains the complete $2 \mu$ DNA sequence (Beggs, 1978). Under non-selective growth conditions we have shown that a reduction in the growth rate of the culture leads to a rapid loss of plasmid from the cells. It can be hypothesized that such a loss occurs as a result of selection, a breakdown in segregation or a combination of these events. In this paper we report on the relationship between the stability and copy number of the plasmid pJDB248 and compare its behaviour with the native $2 \mu$ plasmid.

\section{METHODS}

Yeast strains. The S. cerevisiae strains used were derivatives of S150-2B (a leu2-3,112 his3- $\Delta$ trp1-28 ura3-52) originating from J. Hicks (Cold Spring Harbor Laboratory, New York, USA). S1 50-2B(cir ${ }^{\circ}$ ) was transformed with the plasmid pJDB248 (Beggs, 1978) using the lithium acetate method (Ito et al., 1983). This plasmid consists of the Escherichia coli plasmid pMB9, a yeast chromosomal DNA fragment carrying the $L E U 2$ gene and the complete $2 \mu$ plasmid (Fig. 1). For the native $2 \mu$ studies the isogenic strain $\mathrm{S} 150-2 \mathrm{~B}\left(\mathrm{cir}^{+}\right)$was used.

Culture conditions. Glucose-limited continuous cultures were carried out at $30^{\circ} \mathrm{C}$ in non-selective defined medium (Wickerham, 1946) containing glucose $\left(0.5 \mathrm{~g}^{-1}\right)$, uracil, tryptophan, histidine $\left(10 \mathrm{mg}^{-1}\right)$ and leucine (40 $\mathrm{mg} \mathrm{l}^{-1}$ ). The working volume of the chemostat vessel was $960 \mathrm{ml}$, air flow rate $1000 \mathrm{ml} \mathrm{min}^{-1}$ and agitation rate 650 r.p.m. Biomass was monitored by optical density measurements at $600 \mathrm{~nm}$.

Plasmid stability measurements. The retention of pJDB248 was followed by two methods: replica plating and colony hybridization. The stability of the native $2 \mu$ plasmid was determined by colony hybridization alone.

Replica plating. The proportion of cells in the culture showing leucine prototrophy was determined by initially plating onto YEPD ( $\mathrm{g}^{-1}$ : yeast extract, 10 ; bactopeptone, 20; glucose 20). Replica plating was then carried out onto defined medium (Wickerham, 1946) with and without leucine but with all other appropriate amino acid supplements.

Colony hybridization. Colonies from YEPD plates were selected at random and subjected to colony hybridization by the method given in Sherman et al. (1982), using ${ }^{32} \mathrm{P}$-labelled pJDB41 (Beggs, 1978) as a probe. pJDB41 contains the complete $2 \mu$ DNA sequence cloned into pBR322 and thus is homologous to the $2 \mu$ plasmid and to a large part of pJDB248 but has no homology to chromosomal DNA.

Preparation of total yeast DNA. This was done by physical cell disruption (using glass beads), following the method of Piper et al. (1986).

Measurement of copy number. Total yeast DNA was digested with EcoRI, fractionated by agarose gel electrophoresis and transferred to nylon filters (Genescreen Plus, Dupont) by the method of Southern (1975). Hybridization probes were labelled with either ${ }^{32} \mathrm{P}$ or ${ }^{35} \mathrm{~S}$ using a standard nick-translation kit (Amersham). Blots for pJDB248 copy number estimations were hybridized either with YIP1 (Struhl et al., 1979), which is homologous to a part of the pMB9-derived region of the plasmid and an area of yeast chromosomal DNA around the single copy HIS3 gene, or with pY1rA12 (Petes et al., 1978), which carries the multi-copy yeast ribosomal DNA genes. For experiments involving the native $2 \mu$ plasmid, blots were hybridized with YEP6 (Struhl et al., 1979), which is homologous to $2 \mu$ sequences and the chromosomal HIS 3 gene. 


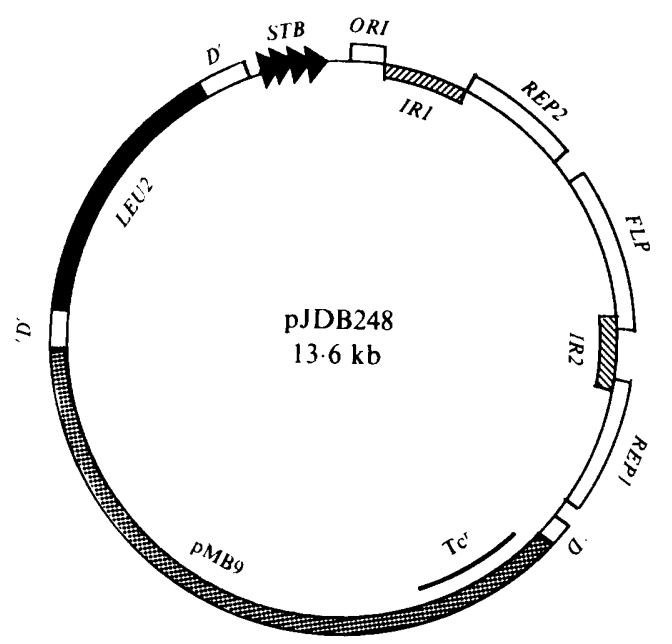

Fig. 1. Diagram of plasmid pJDB248, which contains the bacterial plasmid pMB9, the yeast $L E U 2$ gene and the entire $2 \mu$ plasmid (A form), showing the four genes (REPI, REP2,FLP and $D$ ), the cisacting loci $(O R I$ and $S T B$ ) and the inverted repeat regions (IRI and $I R 2)$. The $D$ gene is interrupted by two segments of inserted DNA; the three resulting segments are represented by $D^{\prime} D^{\prime}$ and ' $D$.

Hybridization was carried out in $1 \mathrm{M}-\mathrm{NaCl}, 10 \%(\mathrm{w} / \mathrm{v})$ dextran sulphate, $1 \%(\mathrm{w} / \mathrm{v})$ SDS, $100 \mu \mathrm{g}$ denatured salmon sperm DNA ml-1 at $65^{\circ} \mathrm{C}$ for $18 \mathrm{~h}$ (method described in Genescreen Plus Catalog no. NEF-976 (1985): Dupont). The position of the bands in the blots was determined by autoradiography. The amount of hybridization in the plasmid and chromosomal bands was determined from densitometer scans (Bio-Rad vd620) of the autoradiographs. With the single-copy HIS3 probes it was found necessary to cut the bands from the filter and determine radioactivity by liquid scintillation counting to ensure reproducible results.

Copy number was determined relative to the single-copy chromosomal HIS3 or to the initial control of the ribosomal repeat copy number (estimated at 100 copies per haploid genome; Petes et al., 1978). The degree of homology of probe to plasmid and chromosomal or ribosomal DNA was taken into account in the calculations. To test the accuracy of the method, determinations for six individual samples were repeated. In each case copy numbers were reproducible to within $20 \%$.

Determination of the intracellular molecular form of the pJDB248. This was done using the same procedure as described for the measurement of copy number. In this case, however, total undigested yeast DNA was hybridized with pJDB248.

\section{RESULTS}

The kinetics of loss of the leucine independent phenotype has been compared in 'fast'$\left(D=0.12 \mathrm{~h}^{-1}\right)$ and 'slow'- $\left(D=0.05 \mathrm{~h}^{-1}\right)$ growing continuous cultures of $S$. cerevisiae S150$2 \mathrm{~B}\left(\mathrm{cir}^{\circ}\right)(\mathrm{pJDB} 248)$. Three separate experiments were carried out and reproducible results obtained. Data representative of one of these experiments are shown in Table 1 and Fig. 2. The percentage of leucine prototrophs decreased in both cultures but the loss was much faster (in terms of generation number) in the 'slow'-growing cells. The rate of loss per generation for the 'fast' culture was 0.0106 and for the 'slow' culture 0.0971 .

Results of this type were interpreted by Kleinman et al. (1986) as indicating a loss of plasmid from the leucine-requiring cells. Such results are, however, also consistent with mechanisms based on genetic instability of the plasmid such as deletion of the LEU2 gene from the plasmid. The loss of plasmid was thus directly tested for by colony hybridization with the $2 \mu$ probe pJDB41, which is homologous to pJDB248 but has no homology to chromosomal sequences. Samples were taken at various times from both 'fast'- and 'slow'-growing continuous cultures. A total of $494 \mathrm{Leu}^{-}$and $84 \mathrm{Leu}^{+}$colonies were analysed. In every case, the $\mathrm{Leu}^{+}$colonies all showed strong hybridization whereas the $\mathrm{Leu}^{-}$colonies showed no homology to the probe. It can thus be concluded that loss of the leucine-independent phenotype is concomitant with plasmid loss and that the results do indeed represent a differential rate of plasmid loss at the two growth rates. 


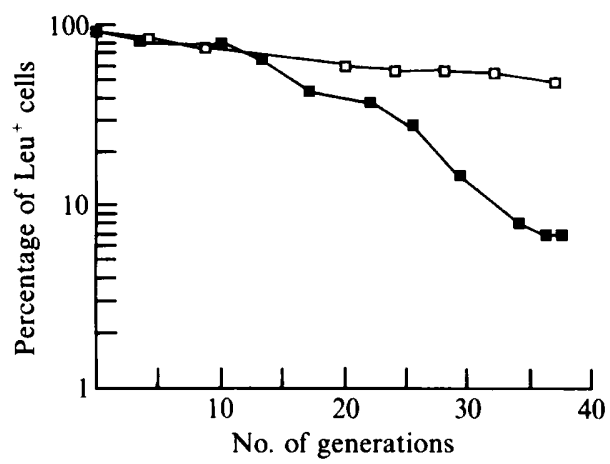

Fig. 2

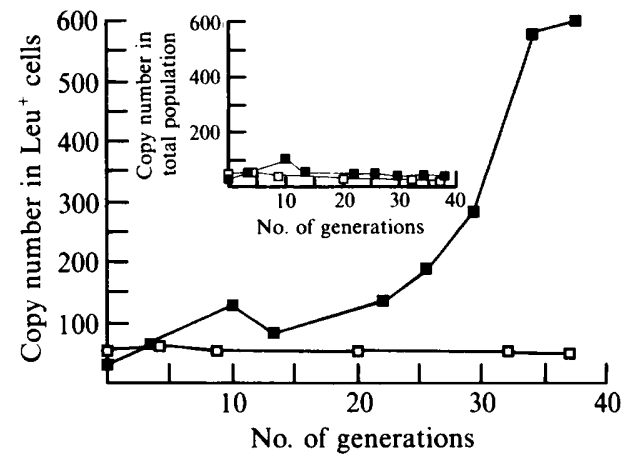

Fig. 3

Fig. 2. Kinetics of loss of leucine prototrophy from $S$. cerevisiae $\mathbf{S} 150-2 \mathrm{~B}\left(\mathrm{cir}^{0}\right)(\mathrm{pJDB} 248)$ in glucoselimited chemostat culture maintained at dilution rates of $0.12 \mathrm{~h}^{-1}(\square)(5.8 \mathrm{~h}$ generation time; 'fast') and $0.05 \mathrm{~h}^{-1}(\mathbb{D})(13.8 \mathrm{~h}$ generation time; 'slow'). The number of generations taken to reach a steady cell density was 8 and 15 respectively. The $\mu_{\max }$ for $S$. cerevisiae $S 150-2 B\left(\operatorname{cir}^{0}\right)(\mathrm{pJDB} 248)$ is $0.31 \mathrm{~h}^{-1}$ (Kleinman et al., 1986). Colony counts from this experiment are given in Table 1.

Fig. 3. Plasmid copy number estimations for plasmid-containing cells of $S$. cerevisiae S150$2 B\left(\operatorname{cir}^{0}\right)(\mathrm{pJDB} 248)$ growing in the 'fast' $(\square)$ and 'slow' $(\square)$ continuous cultures described in Fig. 2. The rDNA probe pY1rA12 was used for the copy number estimations. The inset shows the same data recalculated to take into account the plasmid non-containing as well as plasmid-containing cells, giving overall plasmid copy number.

Table 1. Phenotypic analysis of colonies from glucose-limited continuous cultures of $S$. cerevisiae S150-2B $\left(\mathrm{cir}^{0}\right)(\mathrm{pJDB} 248)$ maintained at 'fast' and 'slow' growth rates

The results are from the experiment shown in Fig. 2. Cultures were maintained at dilution rates of $0.12 \mathrm{~h}^{-1}\left(5.8 \mathrm{~h}\right.$ generation time; 'fast') and $0.05 \mathrm{~h}^{-1}(13.8 \mathrm{~h}$ generation time; 'slow'). Colonies were replica-plated from YEPD onto defined medium with leucine (non-selective medium) and without leucine (selective medium) The results shown for each sample represent the sum of counts from five plates.

(a) 'Fast'-growing culture

No. of colonies on:

$\begin{array}{ccc}\begin{array}{c}\text { No. of } \\ \text { generations }\end{array} & \begin{array}{c}\text { Non-selective } \\ \text { medium }\end{array} & \begin{array}{c}\text { Selective } \\ \text { medium }\end{array} \\ \text { Inoculum } & 173 & 164 \\ 0 & 298 & 270 \\ 4 \cdot 2 & 156 & 130 \\ 8 \cdot 8 & 168 & 124 \\ 20 \cdot 0 & 372 & 219 \\ 24 \cdot 2 & 307 & 171 \\ 28 \cdot 1 & 366 & 208 \\ 32 \cdot 2 & 248 & 135 \\ 37 \cdot 0 & 175 & 84\end{array}$

(b) 'Slow'-growing culture

No. of colonies on:

$\begin{gathered}\text { No. of } \\ \text { generations }\end{gathered}$
Inoculum
0
$3 \cdot 4$
$10 \cdot 0$
$13 \cdot 4$
$17 \cdot 1$
$22 \cdot 1$
$25 \cdot 6$
$29 \cdot 4$
$34 \cdot 2$
$36 \cdot 3$
$37 \cdot 7$

$\begin{array}{cc}\begin{array}{c}\text { Non-selective } \\ \text { medium }\end{array} & \begin{array}{c}\text { Selective } \\ \text { medium }\end{array} \\ 524 & 498 \\ 374 & 349 \\ 539 & 443 \\ 415 & 326 \\ 273 & 176 \\ 243 & 105 \\ 445 & 165 \\ 361 & 101 \\ 551 & 80 \\ 613 & 46 \\ 568 & 42 \\ 491 & 35\end{array}$

The increased rate of plasmid loss in the 'slow'-growing culture could be due to a number of factors: a reduced rate of plasmid replication, a breakdown in segregation, or selection against plasmid bearing cells. To help distinguish between these possibilities, the copy numbers of plasmids in the 'fast' and 'slow' cultures was determined. Fig. 3 shows plasmid copy numbers in the two cultures, with results presented to show mean copy number in the cells which retain the plasmid. At the 'fast' growth rate the plasmid level remained constant; however, at the 'slow' 
Table 2. Stability of native $2 \mu$ and pJDB248 plasmids in glucose-limited continuous cultures of $S$. cerevisiae S150-2B maintained at 'fast' and 'slow' growth rates

\begin{tabular}{|c|c|c|c|}
\hline \multirow[b]{2}{*}{ Plasmid } & \multicolumn{3}{|c|}{ Percentage of plasmid-containing cells } \\
\hline & Inoculum & 'Fast' growth" & 'Slow' growth $\dagger$ \\
\hline $\begin{array}{c}2 \mu \\
\text { DDB248 }\end{array}$ & & $\begin{array}{l}93 \cdot 5 \\
48 \cdot 0\end{array}$ & $95 \cdot 8$ \\
\hline pJDB248 & $95 \cdot 0$ & & $7 \cdot 1$ \\
\hline
\end{tabular}

* The dilution rate was $0 \cdot 12 \mathrm{~h}^{-1}(5.8 \mathrm{~h}$ generation time). Samples were taken at 107 generations for $2 \mu$, 37 generations for pJDB248.

† The dilution rate was $0.05 \mathrm{~h}^{-1}(13.8 \mathrm{~h}$ generation time). Samples were taken at 62 generations for $2 \mu$, 37 generations for pJDB248.

growth rate a dramatic increase in the plasmid level was observed. This increase coincided with the rapid decrease in numbers of plasmid-containing cells in the population (Fig. 2). Hence, after 38 generations, while the number of plasmids in cells growing at the 'fast' growth rate remained around 50, at the 'slow' growth rate the level was around 600 in the minority of cells that retained the plasmid. When the results were considered in terms of the overall copy number in the population (i.e. averaged over plasmid-containing and non-containing cells) they were very similar in both 'fast' and 'slow' growing cultures, and in each case the overall plasmid level remained relatively constant throughout the run (Fig. 3 inset). From these results it is clear that the replication of the plasmid was not inhibited in the 'slow'-growing cells. Rather, the accumulation of the plasmids in a small number of cells indicates a breakdown in segregation.

The experiments were repeated using the probe YIP1, with a single-copy nuclear marker, to eliminate the possibility that some of the effects that we have described were due to variations in rDNA copy number in the different growth conditions. The results from this repeat run were similar to those obtained previously; after 30 generations the difference in plasmid level in plasmid-containing cells at 'fast' and 'slow' growth rate was approximately five-fold.

Investigations in bacteria have shown that instability of plasmids can be associated with the build-up of multimeric forms (Sherratt, 1986). To eliminate this possibility as an explanation of our results we looked at the intracellular form of the plasmid pJDB248. Uncut yeast total DNA from both 'fast'- and 'slow'-growing cultures was probed with pJDB248. The results obtained showed identical patterns for both 'fast'- and 'slow'-growing cultures, with only monomeric forms being detected and no evidence of multimeric forms of the plasmid.

Our investigations into plasmid stability were extended to studies of the native $2 \mu$ plasmid in continuous culture under similar conditions to those used for pJDB248. Results of experiments with $S$. cerevisiae $\mathrm{S} 150-2 \mathrm{~B}\left(\mathrm{cir}^{+}\right)$(containing only the native $2 \mu$ plasmid and no chimeric plasmid) at both 'fast' and 'slow' growth rates over 107 and 62 generations respectively show high plasmid stability (Table 2). For the 'fast' growth rate $\left(D=0.12 \mathrm{~h}^{-1}\right) 93.5 \%$ of the cells retained the plasmid whereas at the 'slow' growth rate $\left(D=0.054 \mathrm{~h}^{-1}\right) 95.8 \%$ retained the plasmid. These results imply that the stability of the native $2 \mu$ plasmid is growth rate independent. In addition, copy number estimations on these cultures revealed that copy number remained constant $(25$ copies per plasmid-containing cell) and showed no differences between cells growing at 'fast' and 'slow' growth rates.

\section{DISCUSSION}

We have shown that the stability of the plasmid pJDB248 is growth rate dependent; at 'slow' growth rates there is a rapid decrease in the percentage of plasmid-containing cells (Fig. 2). The work in this paper clearly demonstrates that a breakdown in plasmid partitioning must be responsible for at least part of this phenomenon. Plasmid copy number determinations showed that the overall level of plasmid in the total population remained constant (Fig. 3 inset) (i.e. the number of plasmid replications is the same). However, the distribution of plasmid in the population was such that a small percentage of the population contained a very high level of 
plasmid, the majority being plasmid-free. Such segregational breakdowns have been demonstrated with other plasmids (Murray \& Szostak, 1983) although none of these plasmids have contained the complete $2 \mu$ genome.

While the results clearly demonstrate a segregational breakdown, consideration must also be given to the possibility that selection against plasmid-containing cells had some role in the rate of plasmid loss, particularly in view of the heavy plasmid loading in these cells. Evidence for a slight growth rate advantage ( $1 \%$ ) in plasmid-free cells has been reported by Mead et al. (1986a) in $2 \mu$ plasmid continuous culture experiments and by Futcher \& Cox (1983) in batch culture. It is possible that a more intense selection at 'slow' growth rates may play a role in the results we have observed. Such selection could result from the load associated with the maintenance of the plasmid itself or with the expression of the inserted sequences, namely the LEU2 and bacterial gene sequences. Nonetheless, the lack of reduction in the overall plasmid level in the population as a whole argues against a powerful role for selection in the rapid loss of plasmid in the 'slow' growth rate cultures.

Our results with the native $2 \mu$ plasmid in glucose-limited continuous cultures are in agreement with those of Futcher \& Cox (1983) and Cashmore (1984) in showing high mitotic stability with production of $2 \mu$-free cells occurring at low frequencies. Although $100 \%$ stability was not observed the proportion of cells retaining the $2 \mu$ plasmid remained high (approximately $95 \%$ ) and was independent of the growth rate, unlike the behaviour of the $2 \mu$-based chimeric plasmid pJDB248 (Table 2).

It is clear that plasmid stability is highly complex, involving host/plasmid interaction and being dependent on specific physiological conditions. The factors involved may not be general but specific to plasmid or host/plasmid combinations. It may seem anomalous that the plasmid pJDB248, which contains the entire $2 \mu$ DNA sequence, is unstable whereas under similar conditions the $2 \mu$ plasmid is stable. While this difference may be due to the greater size of pJDB248, or even to the presence of the bacterial DNA, the importance of the functional region interrupted in the construction of this plasmid must be considered. pJDB248 was constructed by placing insert DNA into the ORF (open reading frame) $D$ region of the $2 \mu$ plasmid (Beggs, 1978). Until recently, this seemed a sensible position for such insertions as no function had been attributed to this region. Recent reports have, however, suggested a role for the $D$ region in plasmid maintenence (Murray et al., 1987; Cashmore et al., 1988). Whilst details of the action of the $D$ region gene product are not fully clear, there is evidence that it acts to derepress the $F L P$ gene and hence promote the $F L P$-mediated system for increasing copy number. Murray et al. (1987) have proposed that the $D$ region gene is itself normally repressed by the $R E P I$ and $R E P 2$ gene products, but that under conditions of low copy number this repression is lifted and plasmid amplification can proceed. It is not immediately obvious how loss of such an activity would result in the restriction of the plasmid to a few cells with high copy numbers. It could be postulated, however, that it is the condition of slow growth itself, with its consequential small bud size, that is responsible for the distortion of the segregational pattern and that the loss of the $D$ gene product exacerbates this distortion by not allowing the copy number in buds to recover to normal levels. We are currently attempting to differentiate between these effects by investigating plasmid stability and copy number in different plasmid constructions, in particular those which are not interrupted in this region.

\section{REFERENCES}

BEgGS, J. D. (1978). Transformation of yeast by a replicating hybrid plasmid. Nature, London 275 , 104109.

BROACH, J. R. (1981). The yeast plasmid $2 \mu$ circle. In The Molecular Biology of the Yeast Saccharomyces: Life Cycle and Inheritance, pp. 445-470. Edited by J. N. Strathern, E. W. Jones \& J. R. Broach. Cold Spring Harbor, NY: Cold Spring Harbor Laboratory.
BroACH, J. R. (1983). Construction of high copy yeast vectors using $2 \mu$ circle sequences. Methods in Enzymology 101, 307-325.

CASHMORE, A. M. (1984). Factors involved in the maintenence of plasmids in yeast. $\mathrm{PhD}$ thesis, CNAA.

Cashmore, A. M., Albury, M. S., Hadfield, C. \& Meacock, P. A. (1988). The $2 \mu \mathrm{D}$ region plays a role in yeast plasmid maintenence. Molecular and General Genetics 212, 426-431. 
Caulcott, C. A. (1984). Competition between plasmid-positive and plasmid-negative cells. Biochemical Society Transactions 12, 1140-1142.

Dobson, M. J., Futcher, A. B. \& Cox, B. S. (1980). Loss of $2 \mu$ DNA from Saccharomyces cerevisiae transformed with the chimeric plasmid pJDB219. Current Genetics 2, 201-205.

Futcher, A. B. (1988). The $2 \mu$ circle plasmid of Saccharomyces cerevisiae. Yeast 4, 27-40.

Futcher, A. B. \& Cox, B. S. (1983). Maintenence of the $2 \mu$ circle plasmid in populations of Saccharomyces cerevisiae. Journal of Bacteriology 154, 612622.

Futcher, A. B. \& Cox, B. S. (1984). Copy number and the stability of $2 \mu$ circle-based artificial plasmids of Saccharomyces cerevisiae. Journal of Bacteriology 157 , 283-290.

Ito, H., Fukuda, Y., Murata, K. \& Kimura, A. (1983). Transformation of intact yeast cells treated with alkali cations. Journal of Bacteriology 153, 163168.

Kleinman, M. J., Gingold, E. B. \& Stanbury, P. F. (1986). The stability of the yeast plasmid pJDB248 depends on growth rate of the culture. Biotechnology Letters 8, 225-230.

Mead, D. J., Gardner, D. C. J. \& Oliver, S. G. $(1986 a)$. The yeast $2 \mu$ plasmid: strategies for the survival of a selfish DNA. Molecular and General Genetics 205, 417-421.

Mead, D. J., Gardner, D. C. J. \& Oliver, S. G. $(1986 b)$. Enhanced stability of a $2 \mu$-based recombinant plasmid in diploid yeast. Biotechnology Letters 8 , 391-396.

Murray, A. W. \& Szostak, J. W. (1983). Pedigree analysis of plasmid segregation in yeast. Cell 34, 961-970.

Murray, J. A. H., Scarpa, M., Rossi, N. \& Cesareni, G. (1987). Antagonistic controls regulate copy number of the yeast $2 \mu$ plasmid. EMBO Journal 6, 4205-4212.

Petes, T. D., Hereford, L. M. \& Skryabin, K. G. (1978). Characterization of yeast ribosomal DNA genes. Journal of Bacteriology 134, 295-305.

Piper, P. W., Curran, B., Davies, M. W., LockHEART, A. \& REID, G. (1986). Transcription of the phosphoglycerate kinase gene of Saccharomyces cerevisiae increases when fermentative cultures are stressed by heat-shock. European Journal of Biochemistry 161, 525-531.

Sherman, F., Fink, G. R. \& Hicks, J. B. (1982). In Methods in Yeast Genetics Laboratory Manual. Cold Spring Harbor, NY : Cold Spring Harbor Laboratory p. 118.

ShERRATT, D. (1986). Control of plasmid maintenance. In Regulation of Gene Expression - 25 Years On, pp. 239-250. Edited by I. R. Booth \& C. F. Higgins, Cambridge: Cambridge University Press.

Southern, E. M. (1975). Detection of specific sequences among DNA fragments separated by gel electrophoresis. Journal of Molecular Biology 98, 503-517.

Struhl, K., Stinchcombe, D. T., Scherer, S. \& DAvis, R. W. (1979). High-frequency transformation of yeast: autonomous replication of hybrid DNA molecules. Proceedings of the National Academy of Sciences of the United States of America 76, 10351039.

Walmsley, R. M., Gardner, D. C. J. \& Oliver, S. G. (1983). Stability of a cloned gene in yeast grown in chemostat culture. Molecular and General Genetics 192, 361-365.

WiCKERHAM, L. J. (1946). A critical evaluation of the nitrogen assimilation tests commonly used in the classification of yeasts. Journal of Bacteriology 52, 293-301. 